REVIEW

\title{
Cardiac amyloidosis: a review and report of a new transthyretin (prealbumin) variant
}

\author{
A Hesse, K Altland, R P Linke, M R Almeida, M J M Saraiva, A Steinmetz, B Maisch
}

Summary

Cardiac amyloidosis is caused by amyloid deposits derived from different human plasma proteins. It can lead to cardiac conduction disturbances, restrictive cardiomyopathy, and low output heart failure. The heart is variably involved during the development of systemic amyloidosis and seems to be more frequently affected in immunoglobulin (primary) than in reactive (secondary) amyloidosis. Amyloid is common in the elderly. Isolated atrial amyloid, for which a major subunit is the atrial natriuretic peptide, seems to be three times more frequent than senile cardiac amyloid, which is derived from normal prealbumin (transthyretin). Like polyneuropathy, cardiac amyloidosis is a prominent clinical feature of hereditary amyloidosis, namely of the autosomal dominant transthyretin (TTR) type. All 28 cases of TTR amyloidoses reported so far were heterozygotes for a single nucleotide change in the gene for TTR that resulted in amino acid substitutions in the mature protein. A new TTR genetic variant is reported in a German family where the index patient presented at the age of 63 with anginal pain and arrhythmia. Electrocardiography was suggestive of a pseudoinfarction pattern, and echocardiography and cardiac catheterisation showed signs of hypertrophic nonobstructive cardiomyopathy with increased ventricular filling pressures and a prominent " $a$ " wave. Amyloid of the TTR type was identified by immunohistochemistry in the endomyocardial biopsy specimen. Hybrid isoelectric focusing established heterozygosity by showing normal TTR protein and an electrically neutral TTR variant differing from all known TTR variants so far. The patient died in an accident before investigations were complete. Electrophoretic analysis of the plasma from his first degree relatives (son, daughter, brother, and mother) identified the asymptomatic 22 year old son as an apparently heterozygous carrier of the mutant TTR protein. Comparative tryptic peptide mapping and sequencing showed that isoleucine at position 68 of the amino acid sequence was replaced by leucine.

(Br Heart f 1993;70:111-115)
Amyloidosis is the term used for a group of diseases characterised by tissue deposition of fibrillar proteins. There proteins bind Congo red and fluoresce in polarised light. ${ }^{1}$ Despite their common morphology these extracellularly accumulated proteins are chemically different and they can be classified according to the deposited protein that is identified by immunohistochemistry or biochemical analysis. The clinical symptoms are generally related to the chemical composition of the deposited proteins.

Immunoglobulin-type (primary) amyloidosis, which is also seen in plasma cell dyscrasia, is caused by the deposition of fibrils derived from immunoglobulin light chains. In individuals with chronic inflammatory disease reactive (or secondary) amyloidosis can develop whereas fibrils formed by a fragment of the acute phase reactant serum amyloid $A$ are deposited. Several other proteins have been identified in amyloid deposits, ${ }^{2}$ the most recently reported being gelsolin. ${ }^{3}$ Genetic variants of the plasma protein prealbumin, now named transthyretin (TTR), cause autosomally dominant inherited forms of amyloidosis. This protein transports thyroxine and retinol and circulates in plasma as a tetramer of identical polypeptide chains of 127 amino acid residues. ${ }^{2}$ Most patients with autosomal dominant amyloidosis of the TTR-type present with peripheral ascending neuropathy (familial amyloidotic polyneuropathy) ${ }^{45}$ and cardiac amyloidosis. ${ }^{67}$

Cardiac involvement is a major problem of immunoglobulin amyloidosis. Most commonly it leads to the ventricular arrhythmias and congestive heart failure that are common causes of death in those patients. ${ }^{8}$ Reactive amyloidosis results mainly in disorders of kidney, intestine, liver, and spleen: cardiac muscle is less likely to be affected. ${ }^{9}$ In contrast in elderly patients infiltration of the heart by amyloid is very common. Two senile forms of infiltration have been identified: (a) amyloid limited to the atria and mainly consisting of atrial natriuretic peptides ${ }^{10}$ which was found in nearly $95 \%$ of octogenerians, ${ }^{11}$ and (b) TTR, which is deposited in both the atria and the ventricles. ${ }^{12}$

Neither of the senile forms is usually recognised in life, though in rare cases they can cause cardiac death. Hereditary amyloidosis, caused by heterozygous TTR variants, can affect the heart as well as the nervous system. Table 1 (adapted from information supplied by Saraiva et $a l^{7}$ ) lists the 28 TTR variants 
Table 1 TTR mutations

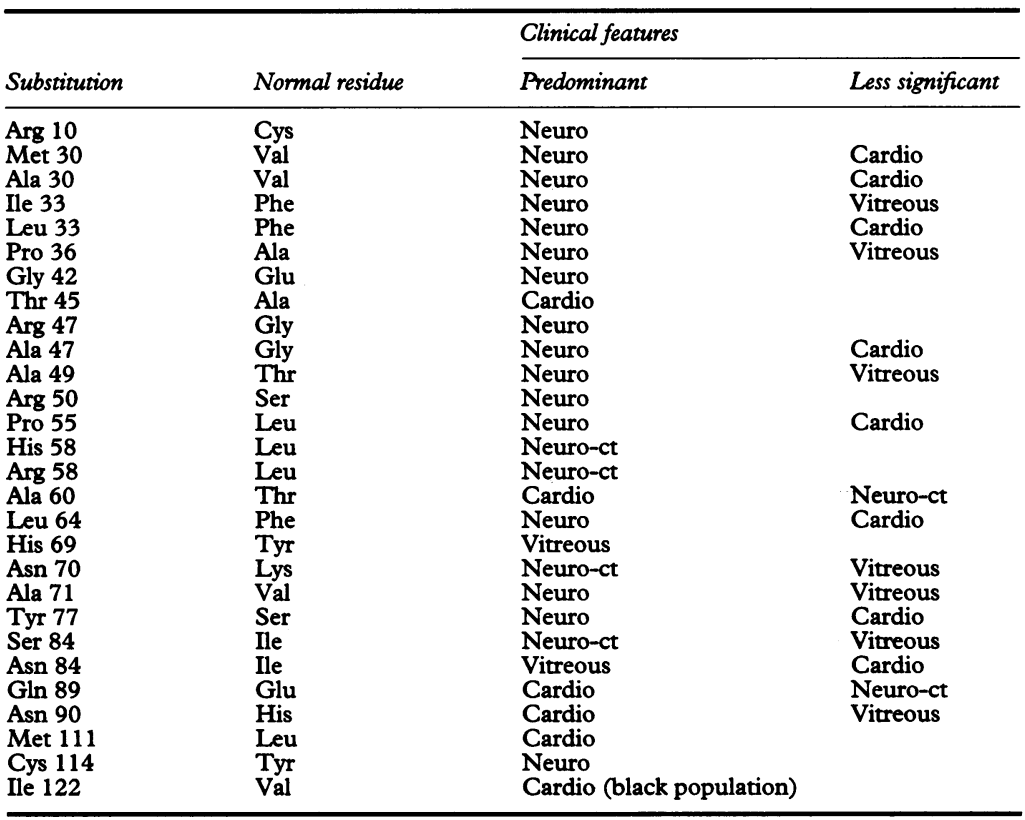

Neuro, neurological symptoms; Cardio, cardiac symptoms; ct, carpal tunnel syndrome; vitreous, ocular symptoms.

known so far and their clinical manifestations.

We report on the clinical and pathological findings in a 63 year old man with cardiac amyloidosis and a hitherto unknown TTR variant.

\section{Methods}

As well as taking a history and performing a physical examination, we examined the propositus, his son, and his daughter by echocardiography, Holter ECG recording, chest $x$ ray and laboratory tests. The propositus was also examined by gastroscopy, rectal biopsy, and cardiac catheterisation with cineangiography and left ventricle endomyocardial biopsy. Paraffin embedded sections of the heart muscle and rectum were examined histochemically with a panel of antiamyloid antibodies directed against various amyloid fibril proteins (AA, A-kappa, Alambda, $\mathrm{AF}, \mathrm{AB}) .^{1314}$

Plasma from the patient and his relatives was examined by double one-dimensional electrophoresis in polyacrylamide gels followed by hybrid isoelectric focusing as described by Altland et al, ${ }^{15}$ modified to study the folding-unfolding reactions of TTR in the presence of urea. TTR concentrations were measured by the Behring nephelometric analysis.

\section{Results}

Patient

The propositus, a dentist, was admitted to hospital in 1988 at the age of 61 with arrhythmia and dyspnoea after bronchitis two months before. He also complained of stomach pain and dysaesthesia in both hands that became worse when he worked. There was a pansystolic murmur at the left sternal edge. The electrocardiogram showed left anterior bundle branch block with small $\mathbf{R}$ waves in leads II, III, aVF, and V1-V4. Echocardiography showed an increase in left atrium diameter $(46 \mathrm{~mm})$ and septal hypertrophy $(27 \mathrm{~mm})$. The Holter electrocardiogram showed arrhythmias of Lown class IVa. The exercise test, chest $x$ ray, laboratory tests, and gastroscopy were normal. Examination did not show any neurological abnormality. No further diagnostic tests were performed and the patient was treated with propafenone.

A year later he was admitted to hospital with signs of congestive heart failure (exercise-induced dyspnoea and mild pretibial oedema). The size of the liver and spleen was normal and there was no ascites. Blood pressure was $100 / 70 \mathrm{~mm} \mathrm{Hg}$. Ultrasound examination of the abdomen was normal. No proteinuria was found. Laboratory investigations showed no evidence of haematological abnormality or infection. Chest $x$ ray showed general enlargement of the heart. The electrocardiogram showed $Q$ waves in leads II, III,
Figure 1

Electrocardiogram from the propositus with cardiac amyloidosis showing a pseudoinfarction pattern with $Q$ waves in leads $I I$ III, aVF, and V1 to V3 (see arrows). Paper speed $50 \mathrm{~mm} / \mathrm{s}$.

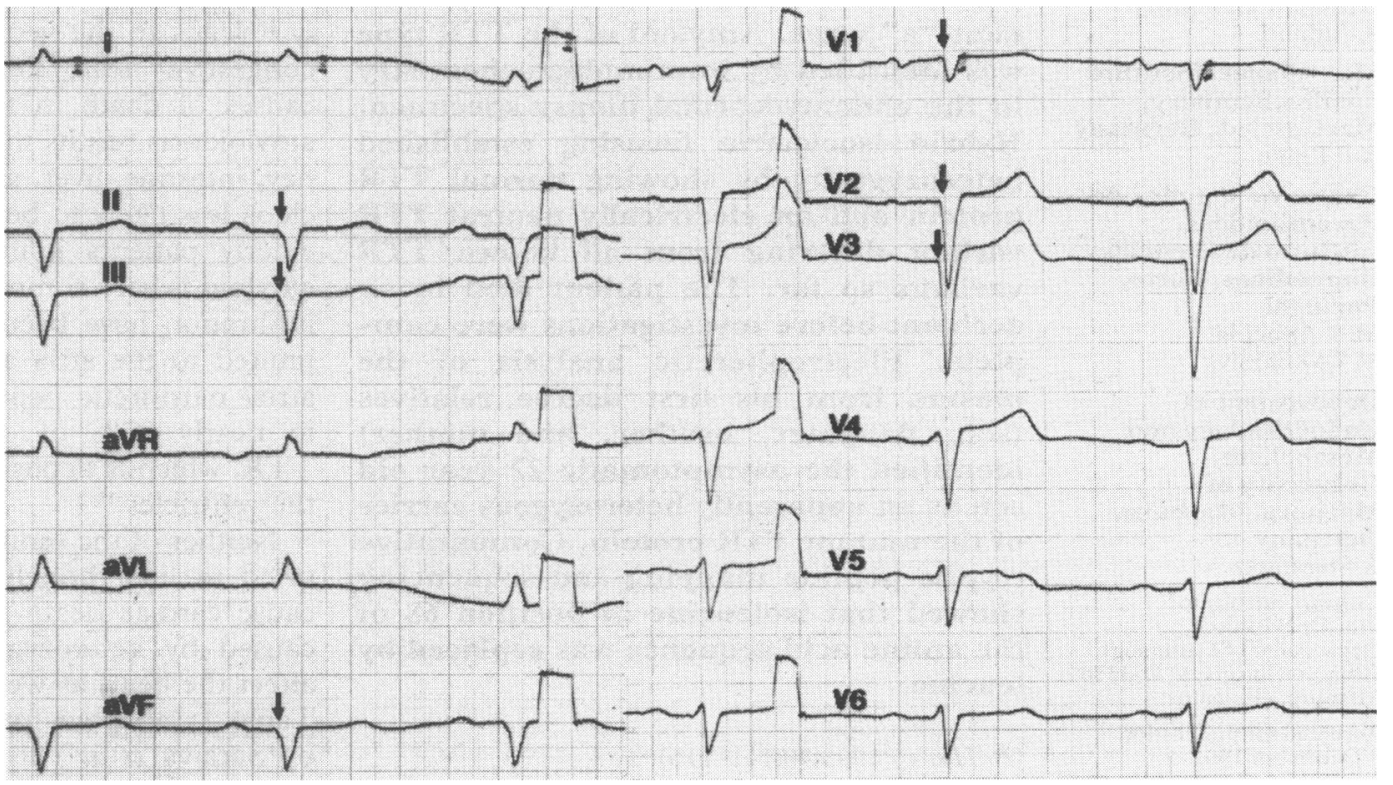




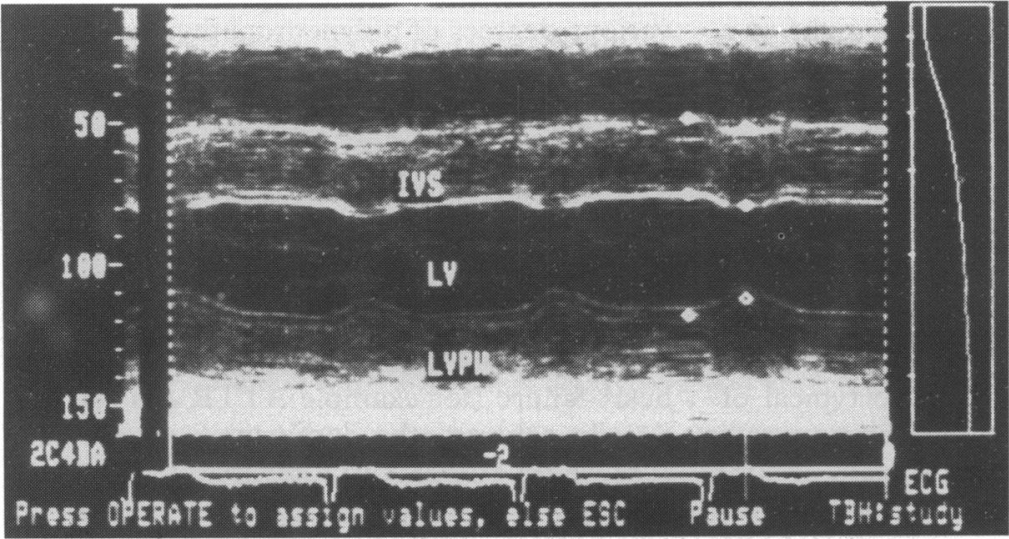

Figure 2 TM echocardiogram of the propositus with cardiac amyloidosis showing a thickened interventricular septum (IVS) and left posterior wall (LVPW) compatible with hypertrophy and non-obstructive cardiomyopathy ( $L V$, left ventricle).

avF, and V1-V3 (fig 1). Echocardiography showed considerable left ventricular hypertrophy with a normal left ventricular end diastolic diameter ( $43 \mathrm{~mm}$ ), a dilated left atrium (diameter $50 \mathrm{~mm}$ ), and a thickened interventricular septum $(28 \mathrm{~mm})$ and left posterior wall $(31 \mathrm{~mm})$, which were compatible with hypertrophic non-obstructive cardiomyopathy (fig 2). Doppler echocardiography showed mild mitral and tricuspid regurgitation. Scintigraphy showed evidence of ischaemia in the inferior, antero-septal, and antero-lateral areas of the myocardium but no scars. Cardiac catheterisation excluded coronary macroangiopathy, and cineangiography showed no focal dyskinesia. An ejection fraction of $69 \%$ confirmed that systolic left ventricular function was normal. The cardiac index $\left(2.8 \mathrm{1} / \mathrm{min} / \mathrm{m}^{2}\right)$ was reduced by an increase in both right $(12 \mathrm{~mm} \mathrm{Hg})$ and left ventricular end diastolic pressures $(35 \mathrm{~mm}$ $\mathrm{Hg}$ ). Pressure in the pulmonary artery was also increased $(20 \mathrm{~mm} \mathrm{Hg})$. In addition, there was a prominent " $a$ " wave, caused by atrial contraction. An endomyocardial biopsy specimen taken from the left ventricle contained amyloid stained by Congo red. Biopsy specimens of the rectal mucosa and submucosa did not stain positively for amyloid deposits. Polyneuropathy was diagnosed on the basis of the patient's complaints of dysaesthesia in both hands and gastric pain. Further studies were planned but shortly afterwards the patient died in an accident

Figure 3 Pedigree of the family of the propositus (II 3, arrow). III 1 is the symptom free son who was a carrier of the TTR variant mutan

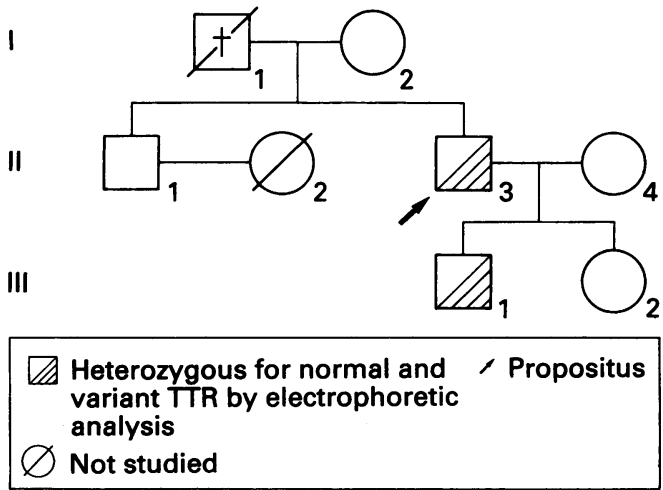

abroad. No necropsy material could be obtained.

\section{HISTOLOGICAL EXAMINATIONS}

Examination of the endomyocardial biopsy specimen of the left ventricle showed extracellular amyloid stained by Congo red that fluoresced under polarised light. Immunoperoxidase staining with anti-AF was strongly positive for the presence of TTRderived amyloid. The control reactions with AA, A-lambda, A-kappa, and AB were all negative.

\section{PROTEIN ANALYSIS}

Electrophoretic analysis showed that both normal TTR and a variant TTR were present in plasma from the propositus and his son. Plasma samples from all the available first degree relatives and the wife of the propositus were normal. The isoelectric point of the variant was indistinguishable from that of the normal TTR monomer, indicating an electrically neutral amino acid substitution in the variant. Other data, which will be published elsewhere, indicated that the conformational stability of the variant TTR monomer was reduced-as it was in other cases of amyloidosis associated with TTR variants (K Altland, unpublished observation).

\section{FAMIIY INVESTIGATION}

The patient's father died at the age of 56 in an accident. His mother, aged 87 , is healthy. Electrophoresis of serum from the mother, from the patient's 60 year old brother, and from the patient's wife and daughter showed normal TTR patterns. The 22 year old son showed normal TTR and an altered TTR protein. Figure 3 shows the pedigree. All the TTR concentrations in serum samples from the family, including the son, $(0.28-0.37 \mathrm{~g} / \mathrm{l})$ were within the normal range (table 2 ).

History, electrocardiogram at rest and exercise, chest $x$ ray, echocardiography, laboratory tests, ophthalmological and neurological examination by electromyography and nerve conduction studies were normal in the patient's daughter, who was examined as a control. The son who was a carrier of the mutant protein, had slightly reduced sensory nerve conductance velocity. He will be followed up prospectively to see whether polyneuropathy develops.

\section{Discussion}

Cardiac involvement in amyloid disease can result in four types of clinical signs. The most common is systolic dysfunction leading to

Table 2 Age and serum TTR in family members

\begin{tabular}{lll}
\hline Family number & Date of birth & $\begin{array}{l}\text { TTR in serum } \\
(\mathrm{g} / \mathrm{l})^{\star}\end{array}$ \\
\hline I 2 & 15 March 1903 & $0 \cdot 37$ \\
II 1 & 11 April 1930 & $0 \cdot 28$ \\
II 3 & 7 Aug 1927 & 0.33 \\
II 4 & 30 Dec 1930 & 0.33 \\
III 1 & 21 March 1968 & 0.34 \\
III 2 & 17 Nov 1969 & 0.34 \\
\hline
\end{tabular}

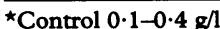


congestive heart failure. ${ }^{8}$ Secondly, signs of a restrictive cardiomyopathy can be prominent $^{16}$-as in our patient orthostatic hypotension can occur. ${ }^{17}$ The least common feature is abnormal cardiac impulse formation and conduction. ${ }^{16}$ All these signs may be variably expressed in one patient. The most striking signs in our patient were those of hypertrophic non-obstructive cardiomyopathy and arrhythmia, leading to exercise-induced dyspnoea. The following findings were typical of cardiac amylidosis: the pseudoinfarction pattern with prominent $Q$ waves in leads II, III, $\mathrm{aVF}$, and V1-V3 and with normal contraction shown by echocardiography. ${ }^{18}$ Roberts and Waller reported this electrocardiographical finding in $83 \%$ of 54 patients with cardiac amyloidosis, but low voltage was not often seen. ${ }^{18}$ Amyloidosis does not necessarily cause the heart to become enlarged. Typically, echocardiography shows abnormal diastolic function owing to rigid walls. Both atria were dilated because of reduced ventricular filling. Hypertrophy of the interventricular septum was confirmed in our patient. Haemodynamic patterns in amyloidosis are not pathognomonic. Increased left and right ventricular filling pressure caused a prominent "a" wave (atrial wave) and reduced the cardiac index. Echocardiographic evidence of thickening of the left ventricle without adequate electrocardiographic signs of hypertrophy strongly suggests the diagnosis cardiac amyloidosis. ${ }^{18} 19$ The diagnosis in our patient was confirmed by endomyocardial biopsy. We excluded reactive AA amyloidosis because there were no signs of chronic infection or evidence of a haematological disorder in a bone marrow aspirate. Because we did not find amyloid deposits in other organs (rectal biopsy specimens) we suspected that our patient had focal senile cardiac amyloidosis characterised by $A S c 1$ (amyloid senile cardiac 1), and the immunohistochemical cross reactions, known to occur with $A S c 1$ and $A F,{ }^{20}$ seemed to confirm this hypothesis. But dysaesthesia and gastric pain reported by the patient were compatible with an inherited form of amyloidosis, first described as familial amyloidotic polyneuropathy. ${ }^{2}$ Subsequent, electrophoretic analysis of serum from the propositus and his relatives detected a TTR variant in both the patient and his son. Amino acid sequencing of the abnormal peptide in the variant showed that isoleucine was replaced by leucine at position 68 . Sequencing of PCR amplified DNA from exon 3 of the TTR gene showed a thymine for adenine substitution in the first base of codon for isoleucine $68 .{ }^{21}$

The 1990 guidelines for nomenclature and classification of amyloid and amyloidosis ${ }^{22}$ indicate the amino acid substitutions that account for the inherited amyloid protein (A for amyloid) variants by a three letter code of the replacement protein followed by the position of the substitution (for example, ATTR Met 30). The ATTR Leu 68 variant we report has not been described before. Reported ATTR variants are associated with various degrees of polyneuropathy, cardiomyopathy, kidney infiltration, ocular alterations, and age of onset. ${ }^{23}$ Three cases have been reported (ATTR Thr 45, Met 111, and Ile 122) with cardiomyopathy as the only organ manifestation (table 1). In 20 of the variants polyneuropathy was the leading feature (for example ATTR Met 30, Ile 33). The remaining eight variants were associated with cardiomyopathy causing death by congestive heart failure (for example ATTR Ala 60, Ser 84). In contrast, the dominant feature in the case we report was cardiomyopathy with early evidence of conduction disturbances. Though our patient showed no evidence of ocular alterations and kidney infiltration, he did have polyneuropathy of the upper extremities and autonomic neuropathy leading to dysaesthesia and gastric pain. The symptoms in his hands could have also been due to carpal tunnel syndrome reported in some TTR variants ${ }^{2}$ rather than an early sign of polyneuropathy. In the kindred we studied, plasma TTR concentrations were normal. In carriers of the ATTR Ser 84 variant they were reduced. ${ }^{2}$ The circumstances of our patient's death prevented more detailed neurological and pathological examination. We detected a slight reduction in sensory nerve conductance velocity in the son. He will be followed up prospectively for cardiac, ophthalmological, and neurological features. In the father cardiomyopathy was expressed late in life, but the son may develop signs of the disease at an earlier age, as did ATTR Ala 60 gene carriers. $^{2}$

Treatment options are more limited in TTR amyloidosis than in primary amyloidosis, where the underlying disease can be treated. In hereditary amyloidosis only symptomatic treatments, such as pacemaker placement for conduction disturbances, are feasible. The lack of an effective medical treatment has led to liver transplantation being tried because the liver is presumed to synthesise the (abnormal) TTR proteins. Liver transplantation in two Swedish patients resulted in the disappearance of variant TTR from the blood and stopped the clinical progression of amyloidotic polyneuropathy. ${ }^{24}$ Prenatal diagnosis of hereditary amyloidosis may make genetic counselling an option in some families. ${ }^{25}$

1 Stone MJ. Amyloidosis: A final common pathway for protein deposition in tissues. Blood 1990;75:531-45.

2 Benson MD, Wallace MR. Amyloidosis. In: Scriver CR, Beaudet AL, Sly WS, Valle D, Stanbury JB, Wyngaarden JB, Fredrickson DS, eds. The metabolic basis of inherited disease. New York: McGraw-Hill, 2439-60.

3 Maury CPJ, Alli K, Baumann M. Complete primary structure of amyloid protein in Finnish hereditary amyloidosis. Identification of a new type of amyloid protein derived from variant (ASN-187) gelsolin. In: Natvig JB, ferived from variant (ASN-187) gelsolin. In: Natvig J B, Westermark P, eds. Amyloid and amyloidosis 1990 . Westermark P, eds. Amyloid and amyloidosis 1990.

4 Harada T, Kito S, Shimoyama M, Katayama S, Sasaki H, Farada T, Kito S, Shimoyama M, Katayama S, Sasaki H,
Furuya $\mathrm{H}$, et al. Genetic and clinical studies of Japanese Furuya $\mathrm{H}$, et al. Genetic and clinical studies of Japanese patients with familial

5 Jacobson DR, Santiago-Schwarz F, Buxbaum JN. Restriction fragment analysis confirms the position 33 
mutation in transthyretin from an Israeli patient (SKO) with familial amyloidotic polyneuropathy. Biochem Biophys Res Commun 1988;153:198-202.

6 Nordlie M, Sletten K, Husby G, Ranlov PJ. A new prealbumin variant in familial amyloid cardiomyopathy of Danish origin. Scand f Immunol 1988;27:119-22.

7 Saraiva MJM, Costa PP, Goodman DS. Transthyretin and familial amyloidotic polyneuropathy. In: Rosenberg RN, Prusiner SB, Di Mauro S, Barchi RL, Kunkel LM eds. The molecular and genetic basis of neurological eds. The molecular and genetic basis

8 Sanchez-Ramos JA, Redondo-Sanchez R, Garcia-Crespo $P$, Superby-Jeldres A, Schuller-Perez A. Cardiac amyloidosis. Cardiovasc Rev Rep 1984;5:524-9.

9 Glenner GG. Amyloid deposits and amyloidosis: The beta-fibrillosis. N Engl $\mathcal{F}$ Med 1980;302:1283-92 and 1333-42.

10 Linke RP, Voigt C, Störkel FS, Eulitz M. N-Termina amino acid sequence analysis indicates that isolated atrial amyloid is derived from atrial natriuretic peptide. Virchows Arch [B] 1988;55:125-7.

11 Steiner I. The prevalence of isolated atrial amyloid. F Pathol 1987;153:395-8.

12 Pitkanen P, Westermark P, Cornwell GG. Senile systemic amyloidosis. Am f Pathol 1984;17:391-6.

13 Linke RP. Immunochemical typing of amyloid deposits after microextraction from biopsies. Appl Pathol 1985;3:18-28.

14 Linke RP, Nathrath WBJ, Eulitz M. Classification of amyloid syndromes from tissue sections using antibodies loid syndromes from tissue sections using antibodies against various amyloid fibril proteins: report of 142
cases. In: Glenner GG, Osserman E, Benditt EP, cases. In: Glenner GG, Osserman E, Benditt EP, Calkins E, Cohen AS, Zucker-Franklin D

15 Altland K, Becher P, Banzhoff A. Paraffin oil protected high resolution hybrid isoelectric focusing for th demonstration of substitutions of neutral amino acids in denatured proteins. The case of four transthyretin (prealbumin) variants associated with familial amyloidotic polyneuropathy. Electrophoresis 1987;8:293-7.

16 Chew C, Ziady GM, Raphael MJ, Oakley CM. The func- tional defect in amyloid heart disease. Am $\mathcal{f}$ Cardiol 1975;36:438-44

17 Saffitz JE, Sazama K, Roberts WC. Amyloidosis limited to small arteries causing angina pectoris and sudden death Am $₹$ Cardiol 1983;51:1234-8.

18 Roberts WB, Waller BF. Cardiac amyloidosis causing cardiac dysfunction. Analysis of 54 necropsy patients Cardiol 1983;52:137-9.

19 Meaney E, Shabetai R. Cardiac amyloidosis, constrictive pericarditis, restrictive cardiomyopathy. Am $f$ Cardiol pericarditis, restrict

20 Linke RP. Immunohistochemical identification and cross reactions of amyloid fibril protein in senile heart and amyloid in familial polyneuropathy. Lack of reactivity with cerebral amyloid in Alzheimer's disease. Clin Neuropathol 1982;1:172-82.

21 Almeida MR, Hesse A, Steinmetz A, Maisch B, Altland $K$, Linke RP, et al. Transthyretin Leu 68 in a form of cardiac amyloidosis. Basic Res Cardiol 1991; 86:567-71.

22 Husby G, Araki S, Benditt E, Benson MD, Cohen AS, Frangione B, et al. The 1990 guidelines for nomenclature and classification of amyloid and amyloidosis. In: Natvig JB, Forre O, Husby G, Husebekk A, Skogen B Sletten $K$, Westermark $P$, eds. Amyloid and amyloidosis 1990. Dordrecht: Kluwer Academic Publishers, 1991; 7-11.

23 Saraiva MJM, Costa PP. Molecular biology of amyloidogenesis in the transthyretin related amyloidoses. In: genesis in the transthyretin related amyloidoses. In: Nletten K, Westermark P, eds. Amyloid and amyloidosis 1990. Dordrecht: Kluwer Academic Publishers, 1991; 1990. Do9-74.

24 Holmgren G, Steen L, Ekstedt J, Groth C-G, Ericzon B$\mathrm{G}$, Eriksson $\mathrm{S}$, et al. Biochemical effects of liver transplantation in two Swedish patients with familial amyloidotic polyneuropathy (FAP-met 30). Clin Gene 1991;40:242-6.

25 Morris M, Nichols W, Benson M. Prenatal diagnosis of hereditary amyloidosis in a Portuguese family. $\mathrm{Am}$ Med Genet 1991;39:123-4. 